\title{
Reflections on Noun-to-Verb Conversion In English ${ }^{\star}$
}

\author{
HEIKE BAESKOW
}

\begin{abstract}
English denominal verbs formed by conversion adopt complex morphosyntactic and semantic information in a rather mysterious way. For example, the lexical item bottle is unambiguously interpreted as a referential expression in a sentence like John bought a bottle of wine, but how do we account for the event-reading of the same lexical item in a sentence like John bottled the wine? In this study it will be argued that the lexical information of converted denominal verbs is not provided by an unspecified zero-affix, but by conceptual qualia structures, i. e. by modes of explanation, and that these make explicit the implicit knowledge speakers of English have about the referents of nominal bases and determine the interpretation and formation of the corresponding verbs. Moreover, qualia structures yield not only the basic meanings of denominal verbs, but also allow for context-dependent interpretations, which are a result of coercion (e.g. John bottled the spectators). A mapping relation between qualia structures and argument structures, the latter of which are part of the lexical representation of the denominal verbs, will be established by meaning postulates.
\end{abstract}

Keywords: word-formation, conversion, lexicon, qualia structures, coercion, proto-roles

* I would like to thank Gisa Rauh, Thilo Tappe, Stefan Engelberg, Colin Foskett, Patrick Deegan, the participants of the linguistic colloquium held at the University of Wuppertal and two anonymous reviewers for helpful comments on this study. Remaining mistakes are however my responsibility. I am particularly indebted to the Fritz Thyssen Stiftung (Cologne), whose financial support enabled me to complete the work on this study, which is part of the project on "Word-Formation and the Lexicon" supervised by Gisa Rauh. 


\section{Introduction}

A peculiarity of the English vocabulary is its rich inventory of verbs which are formed from nouns by conversion or zero-derivation, e. g. to bottle, to butter, to bark, to hammer, to author, to beggar, to concertina and many more. Superficially, these forms do not differ from their nominal bases because they lack an overt derivational affix. Nevertheless, they convey the complex morpho-syntactic and semantic information of the traditional category verb, which does not seem to be inherent to their nominal bases. This study addresses the question of how nominal items adopt properties which are typically associated with the traditional category 'verb' from a new perspective.

The paper is structured as follows: Section 2. is designed as an introduction to the verbs under consideration. In 2.1. it will be argued that the denominal verbs to be examined here are products of conversion rather than of zero-derivation for several reasons. From a semantic point of view, denominal verbs form a variety of distinctive classes, some of which will be introduced in 2.2. Section 2.3. will present a critical overview of some influential theories dealing with noun-to-verb conversion. In contrast to traditional approaches (e.g. Marchand 1969, Zandvoort 1972, Adams 1973), which simply assign dictionary-like paraphrases to products of noun-to-verb conversion (e. g. to bottle "to put something in a bottle"), modern approaches such as those developed by Clark \& Clark (1979), Karius (1985) and Dirven (1999) recognize that the interpretation of denominal verbs as well as the formation of neologisms presuppose a high degree of world-knowledge. However, none of these theories explicitly states where this kind of extra-linguistic information comes from, how it is formally associated with the base nouns and how it determines the semantics of the converted verbs. The works by Hale \& Keyser (1993, 1997, 2002) are particularly disadvantageous because their analyses fall back on paraphrases.

Section 3., which conveys the central idea of this study, is devoted to a formal description of noun-to-verb conversion. Since the interpretation of denominal verbs strongly depends on our extra-linguistic knowledge about the referents of the base nouns, the idea presented here describes this kind of non-lexical knowledge in the form of qualia structures. Qualia structures (henceforth abbreviated to QSs) have their origin in the theory of aitia, i. e. the metaphysical theory of understanding introduced by Aristotle and revived by Moravcsik $(1975,1981,1990)$. They are also an essential ingredient of the Generative Lexicon developed by Pustejovsky (e. g. 1996, 1998, 2001, 2003). However, contrary to Pustejovsky, it will be assumed here that QSs do not express lexico-semantic relations but conceptual relations which are associated with the referents of the 
base nouns and which help to create conceptual events. The mapping relation between the conceptual events, which are assigned QSs as well, and the concrete argument structures the denominal verbs finally display in their lexical entries is mediated by Neo-Davidsonian meaning postulates, which are part of the semantic representation of these verbs. In section 3.1., the analysis will consider institutionalized, i. e. established denominal verbs with fixed meanings. ${ }^{1}$ In 3.2. and 3.3. it will be shown that even context-dependent meaning components of denominal verbs do not arise independently of QSs, and we shall extend our view to neologisms and to innovative uses of institutionalized denominal verbs.

\section{A preliminary account}

2.1. The notions of zero-derivation and conversion

In the previous section it was indicated that verbs like to bottle, to butter, to author etc. are formed from their nominal bases without affixes, or, to put it more carefully, at least without visible affixes. Authors such as Jespersen (1942), Marchand (1969) and Adams (1973) claim that verbs of this kind are derived from the corresponding nouns by means of a zero-morph or zero-affix $\emptyset$. From this point of view, we are dealing with a particular type of derivation, namely with zero-derivation. The zeromorph seems to be motivated by the semantic and functional parallels between zero-marked items and items carrying overt derivational suffixes, e. g.

$$
\begin{aligned}
& \text { a. } \text { alcohol }_{[+ \text {common }]} \rightarrow \text { alcoholize }_{[+ \text {dynamic }]} \\
& \text { "prepare, treat with alcohol" } \\
& \text { b. paraffin }[+ \text { common }] \rightarrow \text { paraffin } \emptyset_{[+ \text {dynamic }]} \\
& \text { "prepare, treat with paraffin" }
\end{aligned}
$$

According to the Overt Analogue Criterion (OAC) discussed by Sanders (1988), the recognition of a zero-marked relation (like the one in (1b)) is due to the existence of a corresponding relation involving overt morphological marking (like the one in (1a)). Note that this observation also holds for inflection, e. g. [cat $]_{\mathrm{Sg}}$ : [cat s$]_{\mathrm{Pl}}=[\text { sheep }]_{\mathrm{sg}}$ : [sheep $\left.\emptyset\right]_{\mathrm{Pl}}$. However, the OAC does not always hold between affixal derivatives and zeroderivatives. Consider for example the following sentences presented by Sanders (1988: $170 \mathrm{f}$.), which illustrate in a striking manner that the socalled zero-derivatives are not in complementary distribution with deriva-

1. According to Bauer (1988: 66f.), words are institutionalized if they come "into general use in the society" and are thus listed in dictionaries. 
tives ending in the overt suffixes -ize, -ify and -ate and in fact differ in meaning when they appear in the same context.

(2) a. She charactered ( $\neq$ characterized) the novel very well.

b. She classed ( $\neq$ classified) the inscriptions as Etruscan.

c. She filtered ( $\neq$ filtrated) the solution.

Another problem with the zero-approach is that we would not only have to postulate a zero-suffix with a rather general meaning, but also a zeroprefix yielding the negative, privative, ablative or reversative meaning components of their overt counterparts un-, de- and dis- (cf. Dokulil 1968, Olsen 1986, Plag 1999). If we follow this line of reasoning, we would have to say that the zero-affixes do indeed have to be associated with very general components of meaning because conversion allows us to establish relations which affixal derivatives cannot express at all, e. g. the instrumental reading of verbs like to hammer or the durative reading of the type to summer. According to Lieber (1981: $120 \mathrm{ff}$.), particularly strong evidence against zero-derivation comes from languages with complex inflectional classes like German. As far as verb-to-noun zero-derivation is concerned, German would require at least three zero-affixes $\emptyset_{\mathrm{i}}$, $\emptyset_{\mathrm{j}}$ and $\emptyset_{\mathrm{k}}$ whose distribution is determined by the plural form of the base noun (e.g. rufen "to call" $\rightarrow$ der Ruf "the call" $\sim$ die Rufe "the calls", klingen "to sound" $\rightarrow$ der Klang "the sound" die Klänge "the sounds", binden "to bind" $\rightarrow$ das Band "the ribbon" die Bänder "the ribbons").

Nevertheless, let us assume for a moment that the lexicon actually includes zero-affixes, and let us briefly discuss the question of what it means for a sign to be a zero-element. In a Saussurean sense, a linguistic sign consists of a sequence of sounds which is related arbitrarily to its meaning. In the case of a zero-affix, this dichotomy is reduced to the aspect of meaning: there is a signifie without a signifiant, so to speak. However, the remaining signifié is not a purely semantic construct, but also carries a set of formal, i. e. morpho-syntactic features which is responsible for its grammatical functions. These properties make it similar to empty categories used in syntax such as PRO or traces (e. g. Chomsky 1986). And yet there is a significant difference, which again results from the OAC. In contrast to the morpho-syntactic and semantic information of empty syntactic categories, the lexical information associated with a zero-affix is not retrievable from a phonetically realized antecedent, and thus remains entirely unmotivated. Since the OAC is bound to fail with respect to zero-derivation, it will be assumed here that the lexical infor- 
mation of the denominal verbs under consideration is not represented by one or more ill-defined zero-morphs. Thus, it seems to be more appropriate to speak of conversion, i. e. of a process which changes a lexical item carrying a particular set of morpho-syntactic and semantic properties into an orthographically and phonetically identical or similar item with different morpho-syntactic and semantic properties. Conversion defined this way, which also accounts for potential orthographic and/or phonetic deviations from the base (e.g. shelf [ $\left.\int \mathrm{elf}\right] \rightarrow$ to shelve [ $\mathrm{felv}]$, house [havs] $\rightarrow$ to house [havz]), makes the close relationship between the verbs and their parent nouns more explicit than the term zero-derivation.

\subsection{Selected semantic classes}

Given the high potential of denominal verbs formed by means of conversion and the broad range of meanings associated with them, the present analysis will be mainly concerned with five representative verb classes. ${ }^{2}$ The first class examined includes verbs like to bottle, to bag, to catalogue, to house, to kennel or to garage, which Clark \& Clark (1979), Karius (1985), Labelle (2000) and Hale \& Keyser (1993, 1997, 2002) refer to as 'location verbs' because they focus on the final location of an entity. Secondly, verbs denoting the entity which is moved from one location to another will be investigated. Considering the direction of movement, we may distinguish between 'ornative verbs' ${ }^{3}$, expressing an entity's movement towards a location (to butter, to nickel, to fringe, to label, to saddle, to paint), and 'privative verbs', expressing an entity's removal from a source position (to bark, to fleece, to skin, to peel, to weed, to milk). Clark \& Clark (1979: $769 \mathrm{ff}$.) label the verbs of both semantic classes 'locatum verbs'. A third class to be discussed here consists of denominal verbs referred to as 'agent verbs' by Clark \& Clark (1979: 773). These verbs display co-reference between the referent of the base noun and the referent of the verb's external argument (e.g. to author, to father, to pioneer). For instance, if Chomsky authored a book, he is the author of that book. Fourthly, verbs of the type to beggar, to knight, to orphan, to widow, or to cripple, which constitute one subgroup of the rather com-

2. The following examples are taken from Marchand (1969), Clark \& Clark (1979) and Karius (1985). According to the OED, the nominal use preceded the verbal use in all cases.

3. The term 'ornative' does not necessarily entail that an entity is decorated with the referent of the base noun in the literal sense. It is used here to categorize true ornatives, e. g. They fringed the cloth with blue elephants as well as verbs which semantically behave like true ornatives, e.g. They staffed the buffet cars with immigrants. Both examples are taken from Karius (1985: 125). 
plex class of 'resultative verbs', will be taken into consideration. Here the base noun denotes the final state of the referent of the verb's internal argument. However, as observed by Clark \& Clark (1979: 775) and Karius (1985: 106), the achievement of such a final state need not be intended. Thus, a sentence like Professor Moriarty widowed the colonel's wife is ambiguous between a purpose-reading (he murdered the colonel in order to marry the colonel's wife) and an external-force reading (he killed the colonel for other reasons, or by accident). In this respect, these verbs differ from the agent verbs introduced above, whose "parent nouns denote roles or professions that people take on deliberately." (Clark \& Clark 1979: 775) According to Burgschmidt (1975: 30), the fifth class to be dealt with here, the one containing 'instrumental verbs' such as to hammer, to nail, to knife, to mop, to bicycle, to stone or to guitar, is the largest semantic class of converted verbs. This is probably due to the fact that English lacks derivatives with an instrumental reading (cf. section 2.1.). This semantic classification is not exhaustive, but provides a representative survey for an analysis of English denominal verbs formed by conversion. Apart from established verbs belonging to the classes just introduced, we shall also consider some neologisms and innovative uses of established verbs in order to extend the theory to be developed here to less basic forms.

\subsection{A critical survey of previous theories on noun-to-verb conversion}

In the literature, noun-to-verb conversion has been described from rather different perspectives. Traditional approaches (e.g. Marchand 1969, Zandvoort 1972, Adams 1973) try to capture the rich semantics of denominal verbs by means of dictionary-like paraphrases, which lack a theoretical foundation and force these verbs into limited interpretative contexts. For instance, if Marchand (1969: 370) abstracts the semantic information "put in _ " from location verbs, he does not account for a sentence like John bottled the spectators (i. e. "John pelted the spectators with bottles"), in which to bottle contextually assumes the status of an instrumental verb.

A syntax-based approach to conversion as proposed by Hale \& Keyser, which makes use of incorporation $(1993,1997)$ or conflation (2002), is rejected here for various reasons. First, such an approach does not inquire into the development of the argument structures associated with denominal verbs. Hale \& Keyser presuppose the existence of the canonical lexical relational structure (LRS) shown in (3), which is rather costly because it differs crucially from postlexical syntactic structures. 
(3)

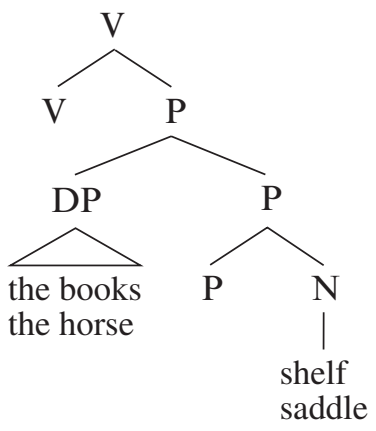

(Hale \& Keyser 2002: 18)

The structure in (3) serves to depict the properties of the empty and hence defective heads $\mathrm{P}$ and $\mathrm{V}$, which make up the lexical items to shelve and to saddle. The syntactic property of the inner head is that it takes a complement (e.g. shelf, saddle) and projects a DP-specifier (e.g. the books, the horse). Moreover, since $\mathrm{P}$ is phonologically empty, it copies the phonological matrix of the complement it has merged with, i.e. the phonological matrix of shelf or saddle. This process, which obeys the Head Movement Constraint, is referred to as conflation. In a next step, the upper V-head, which is phonologically empty as well, conflates with the head $\mathrm{P}$ of its prepositional complement, which itself is a product of conflation. ${ }^{4}$ These processes provide the empty verbal head in (3) with phonological content.

Secondly, the model proposed by Hale \& Keyser fails to describe denominal verbs other than location verbs (e.g. to shelve) and ornative locatum verbs (e.g. to saddle) because their LRS is intended to reflect the constituent structure of the verb put. "These verbs [i.e. location and locatum verbs] are synthetic counterparts of the verb put [...]" (Hale \& Keyser 2002: 18). Note, however, that the LRS in (3) roughly corresponds to the phrase put the books on the shelf, but not to put a saddle on the horse. For (3) to apply to locatum verbs, the authors are forced to choose a different paraphrase, namely She fitted the horse with a saddle, which arbitrarily deviates from the paraphrase involving put. If put is considered responsible for the interpretation of both location and ornative locatum verbs (privative verbs are not accounted for at all), the argument positions of the horse and saddle should be interchanged in (3).

4. In Hale \& Keyser $(1993,1997)$, the nominal complement of P (e.g. shelf, saddle) was moved to the empty V-head via $\mathrm{P}$ and via a lower verbal head. This process was referred to as incorporation. 
Thirdly, the prelexical structure in (3), as it stands, fails to show that shelf and saddle differ with respect to their semantic behaviour. As we shall see in the following section, the objects denoted by locatum verbs (e.g. saddle) are caused to undergo a change of position, whereas the objects denoted by location verbs (e.g. shelf) remain stationary with respect to the movement of another entity, or even constitute a particular type of incremental theme in the sense of Dowty (1991). The latter property will be discussed on the basis of the verb to bottle.

Moreover, as in the paraphrase "put in __" used by Marchand, the base noun appears as a complement to a hypothetical preposition in (3). As a result, the fact that the referent of the base noun may be specified in the form of a hyponymic prepositional object is concealed. Given the English sentences in (4), taken from the British National Corpus (BNC) and Karius (1985), the French sentences in (5), taken from Labelle (2000), and the German sentences in (6), we are obviously dealing here with a cross-linguistic phenomenon. Note that the prepositional object has to provide additional information, i. e. information which is not conveyed by the converted verb.

(4) a. The vinegar is then bottled in the traditional flask and sealed with a cork to preserve its high quality.

b. They nailed the notice to the church door with arrows.

a. Eva cloître [sic!] Luc dans sa chambre. Eva shuts away Luc in his room.

b. Maxfleurit la tombe de géraniums. Max flowers the grave with geraniums.

(6) a. Chico sattelte sein Pferd mit einer Decke. Chico saddled his horse with a rug.

b. Der Trunkenbold wässerte die Pflanze mit Bier. The drunkard watered the plant with beer.

The most serious problem with traditional approaches and the theory developed by Hale \& Keyser is that they neglect an essential extra-linguistic aspect which contributes to a successful interpretation of denominal verbs, namely the aspect of world knowledge. The relevance of world knowledge or everyday knowledge, which is non-definable in terms of dictionary-like paraphrases, is made explicit by Clark \& Clark and Karius. Clark \& Clark (1979: 788) distinguish between generic and particular knowledge. "Generic knowledge is what people tacitly know about space and time, the basic physical laws, natural kinds, manufactured 
artefacts and their functions, and so on." As opposed to particular knowledge, which depends on an individual's environment and experience, generic knowledge is supposed to be relatively invariant and determines the interpretation of established and innovative denominal verbs. The use of innovative denominal verbs is additionally governed by the following convention, which reflects the co-operation principle set up by Grice (1975):

THE INNOVATIVE DENOMINAL VERB CONVENTION. In using an innovative denominal verb sincerely, the speaker means to denote

(a) the kind of situation

(b) that he has good reason to believe

(c) that on this occasion the listener can readily compute

(d) uniquely

(e) on the basis of their mutual knowledge

(f) in such a way that the parent noun denotes one role in the situation, and the remaining surface arguments of the denominal verb denote other roles in the situation.

(Clark \& Clark 1979: 787)

Karius (1985: $43 \mathrm{ff}$.) also emphasizes the relevance of "Alltagswissen", i. e. everyday knowledge, but her definition is less fixed than the one given by Clark \& Clark for generic knowledge. She compares the information components of everyday knowledge to frames, which are variable to a certain degree, but have a constant core. ${ }^{5}$

Similarly, Dirven (1999: 283) considers a "wider experiential scene" to be the real motivation for noun-to-verb conversion. Since denominal verbs evoke scenes and images associated with the referents of the base nouns, he describes noun-to-verb conversion as a particular type of metonymy, namely as an event-schema metonymy, which singles out "a salient participant to become [...] the main designation for the event itself." (Dirven 1999: 279)

Evidently, speakers of English and other languages are able to interpret nouns as verbs because the referents of the nouns serving as bases are associated with particular functions or predominant features which are focussed by the converted verbs. Our knowledge of these functions and features enables us to modify the VPs containing a converted verb

5. According to the frame theory developed by Marvin Minsky in 1975, human beings internalize not only concrete objects, but also stereotyped situations such as the situation of going to a child's birthday party (cf. Minsky e.g. 1982 for an abridged version of the relevant paper). 
like to bottle or to nail (cf. (4)) by means of PPs whose nominal complements are hyponyms of the base noun and thus refer to entities which serve (at least roughly) the same purpose as the referents of the nominal input to the converted verbs. Since a flask is a suitable container for preserving wine, it fulfils a function which is similar to the function of bottles, and nothing prevents us from using arrows, which constitute pointed instruments, to nail notes to a surface in a Robin Hood-like manner.

Approaches to conversion such as those presented by Clark \& Clark, Karius or Dirven are evidently superior to models of description which try to capture the semantic content of denominal verbs by using paraphrases. ${ }^{6}$ And yet, none of the approaches presented so far explicitly states where the generic knowledge we have about the referents of the base nouns comes from, how it is formally represented and how it contributes to the semantics of the corresponding verbs. Even if we describe generic knowledge about the nominal bases by referring to salient situations, frames or event schemata, as proposed by Clark \& Clark, Karius and Dirven respectively, it seems as if we are fundamentally dealing with extra-linguistic information. For instance, when Dirven states that the verb to bottle (in its literal meaning) evokes "the scene of food preservation" (1999: 283), we non-trivially have to ask for the source of such an association. The fact is that there must be something about nouns which enables us to conceptually create scenes, frames or situations and the participants involved in them.

More substantial linguistic theories (e. g. Rauh 1988, Maienborn 1996, Bierwisch 1997) recognize that world knowledge is not part of the grammar or lexicon, but of the conceptual system and thus explicitly dissociate themselves from Jackendoff (e.g. 1987, 1990), who postulates one level of representation for conceptual and semantic information. As far as word-formation is concerned, Plag (2003: 109) states that the interpretation of the verb to bottle "requires the existence of the concept of a bottle", and Lieber's (2004) analysis of conversion (and other wordformation processes) makes use of skeletal semantic features which define a set of conceptual categories. Lexical items of the category 'noun', for instance, are associated with the semantic features [+material] (e.g. bottle) and [-material] (e.g. love) respectively, which represent the conceptual category of SUBSTANCES/THINGS/ESSENCES. However, as pointed out by Lieber (2004: 24), notions like these are somehow awkward because they are "not meant to be primitives themselves, but mnemonic terms that we can use for referring to these large conceptual/ontological

6. Cf. Kiparsky (1997) and Stiebels (1998) for further criticism of the theory proposed by Hale \& Keyser (e. g. 1993, 1997, 2002). 
categories." Once again, the notion of world knowledge or conceptual categories remains vague because the focus of attention is on the semantic representations.

Even a most recent variant of Neo-Construction Grammar, i.e. the one developed by Borer (2005), is not enlightening in this respect. Although world knowledge is an essential ingredient of a theory in which an item (= listeme) is no more than a sound-meaning pair until it is inserted into a particular functional configuration, no attempt is made to inquire into the conceptual system. Hence, a "substantive listeme is a unit of the conceptual system, however organized and conceived, and its meaning, part of an intricate web of layers, never directly interfaces with the computational system." (Borer 2005: 11)

In the following sections it will be suggested that the extra-linguistic knowledge required to interpret and to coin denominal verbs should be represented in the form of conceptual qualia structures, which provide detailed information about the referents of the base nouns and help to create events for the process of verbalization. Moreover, it will be shown that the multi-faceted qualia structures of nouns are not only involved in the interpretation of institutionalized denominal verbs, but also enable us to assign context-dependent meaning components to established verbs (e. g. to bottle the spectators) and neologisms (e.g. to concertina the hat).

\section{A formal approach}

\subsection{Established denominal verbs with institutionalized meanings}

Denominal verbs formed by means of conversion convey complex morpho-syntactic, conceptual, semantic and pragmatic information with no expenditure of morphologically realized material. As outlined in the previous section, an adequate interpretation of these verbs involves world knowledge, in particular generic knowledge, as to the referents of the nominal bases. In a next step we have to ask how world knowledge is formally represented and how it determines the semantics of the denominal verbs. The discussion will proceed from the noun bottle, which is the base of the location verb to bottle and whose lexical entry contains information of the following kind:

LEXICAL ENTRY FOR THE NOMINAL ITEM BOTTLE

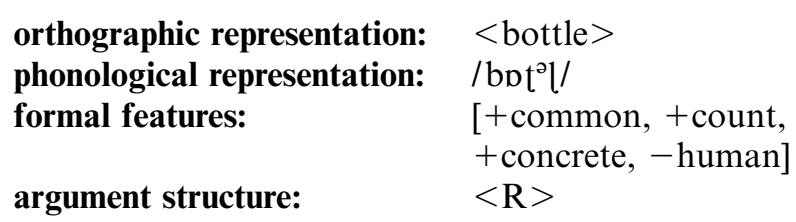


This entry specifies bottle as a common, countable noun which refers to a concrete object and thus licenses a referential argument $\langle\mathrm{R}\rangle$ in the sense of Williams (1981). ${ }^{7}$ Since none of these properties points towards a verbal use of this lexical item, the process of verbalization must be triggered on a non-lexical level of representation. The fact that there is a verb to bottle strongly suggests that the speakers of English ascribe characteristics to the referent of the noun bottle which go beyond the information listed in (8). In order to interpret to bottle, they must activate the information that a bottle is a particular type of container which serves to hold liquid. Of course, there is additional information about bottles which does not contribute to the interpretation of to bottle in its unmarked reading. We know for instance that bottles are artefacts consisting of a particular material, which may be glass or plastic. Moreover, we know that bottles are usually produced by machines. Since all these extra-linguistic characteristics define the concept of a prototypical bottle, they should be specified on the level of conceptual representation. An adequate formal representation of extra-linguistic knowledge associated with lexical items is provided by qualia structures, which are part of the Generative Lexicon developed by Pustejovsky (e.g. 1996, 1998, 2001, 2003). Following the tradition of the Aristotelian aitia, a qualia structure (QS) consists of the four generative factors FORMAL, CONSTITUTIVE, TELIC and AGENTIVE, which define the referent of a lexical item with respect to its distinctive properties (i. e. properties which distinguish it from other entities), its constituency, its purpose or function and its coming into existence. ${ }^{8}$ As far as our example bottle is concerned, the QS of the concept BOTTLE should specify information of the following kind:

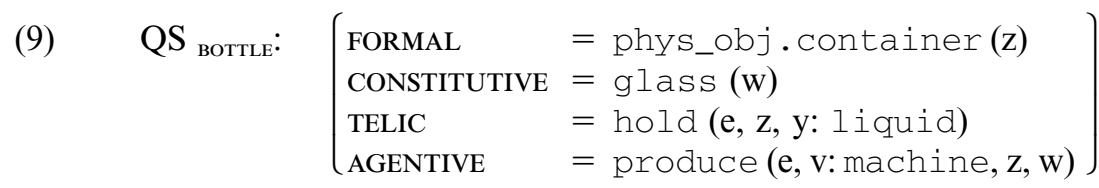

\footnotetext{
7. Note that the formal, i.e. the morpho-syntactically relevant features in (8) make the traditional categorial label ' $\mathrm{N}$ ' (= Noun) predictable and hence redundant (cf. Chomsky 1995, Rauh 2000, Lieber 2004 or Baeskow 2002, 2004 on the advantages of featurebased representations.)

8. Aitiae revealed the nature of objects, processes, propositions etc. in the form of answers to questions introduced by dia $t i$ "why", e. g. "Why does this statue endure?" - "Because it is made of bronze." (Moravcsik 1975: 624)
} 
Each of the four quales in (9) provides a piece of conceptual information, which is referred to as the qualia value. Most importantly, qualia values do not constitute concrete lexical items. According to Anick \& Pustejovsky (1990), they should be conceived of as heuristics which are linguistically reflected by the collocations of the noun they predicate. This property makes them a suitable tool for information retrieval systems such as machine-readable dictionaries and text corpora. In Pustejovsky (1996: 78), qualia values are defined more formally as "expressions with well-defined types and relational structures."

The FORMAL quale in (9) first of all states that the referent of bottle is a physical object, but this characterization is not specific enough because it does not reveal what distinguishes a bottle from other physical objects in a larger domain, e. g. from books or knives. The relevant distinguishing factor is provided by the fact that bottles (as opposed to books or knives) constitute containers. Moreover, since containers are necessarily physical objects, the noun bottle displays logical polysemy and may thus be considered a complex or dotted type in the sense of Pustejovsky (1996: $90 \mathrm{ff}$.), i.e. a type cluster which relates two senses $\sigma_{1}$ and $\sigma_{2}$ of the type hierarchy of bottle.

The CONSTitutive quale specifies the material a bottle is made of. Although glass bottles are being replaced by bottles made of plastic, it is assumed here that the prototype of a bottle is still associated with glass. However, since the information content of a quale is variable within the limits of generic knowledge, the material of a prototypical bottle may be glass for speaker A and plastic for speaker B.

The interaction of the individual quales is accounted for by "binding" the qualia values appropriately. The values of the FORMAL and the CONSTITUTIVE quale are assigned to the conceptual arguments (z) and (w) respectively. These variables reappear on the TELIC and the AGENTIVE quale, where their referents participate in particular events, namely a) in the event associated with the function of a bottle and $b$ ) in the event associated with the coming into being, i.e. the production of a bottle. The TELIC and the AGENTIVE quale additionally specify that the entity (y) in the container $(\mathrm{z})$ should be a liquid and that the entity (v) which makes a bottle (z) out of glass (w) is prototypically a machine. The relevance of the AGENTIVE quale (which must not be confused with the theta-role Agent) might become more obvious in the context of concepts such as NOVEL and DICTIONARY. These concepts differ not only with respect to their function, but also with respect to their coming into being. According to Pustejovsky (1996: 77), a novel comes into being by writing, whereas a dictionary is compiled. Note that the qualia values 
"write" and "compile" are linguistically reflected by the collocations to write a novel and to compile a dictionary.

Up to this point, we have been concerned with the lexical entry for the noun bottle (cf. (8)) and a possible representation of the concept BOTTLE (cf. (9)). In contrast to the lexical entry, which specifies purely nominal features, the conceptual QS provides at least one option for a verbal interpretation of bottle. More precisely, it is the TELIC quale from which the institutionalized verbal reading emerges. If the prototypical function of a bottle is to hold a liquid, the verb to bottle most naturally denotes a causative event which leads to the realization of this function, i. e. the event of putting liquid in bottles. Note that this event, too, is conceptual at this stage of the conversion process because we are still dealing with extra-linguistic information. Therefore, the next step is to postulate a QS for Tо воттLE. According to Pustejovsky (1996: 80), the events denoted by causative predicates typically involve an initial act or process and a resulting state, and these two phases are mapped onto the verbs' AGENTIVE and FORMAL quale respectively. In the case of TO BOTTLE, the FORMAL quale specifies the state (s) of a bottle (or similar container, cf. (4a)) holding a liquid. This is precisely the relation expressed in the TELIC quale of the nominal concept BOTTLE. The AGENTIVE quale of TO BOTTLE reveals that the resulting state represented in the FORMAL quale is initiated by an event in which some unspecified entity (x), which may be a machine or a human being, puts a liquid (y) in a bottle or similar container (z). The QS of то вотTLE is given below:

$$
\mathrm{QS}_{\text {то вотtLe }}:\left(\begin{array}{rl}
\text { FORMAL }= & \text { hold }(\mathrm{s}, \mathrm{z}: \text { phys_obj.con- } \\
& \text { tainer, } \mathrm{y}: \mathrm{liquid}) \\
\text { AGENTIVE }= & \text { put }(\mathrm{e}, \mathrm{x}, \mathrm{y}, \mathrm{z})
\end{array}\right)
$$

Note that Pustejovsky, like Jackendoff (e. g. 1987, 1990, 1997), considers conceptual knowledge to be part of our lexical knowledge. As a result, the QS of a lexical item is integrated into this item's lexical entry. However, if QSs are considered to be conceptual by nature, as in the present study, the argument structures (ASs) which the denominal verbs finally display in their lexical entries and which have to be saturated in the syntax cannot be directly constructed from this level of representation. Thus, we need an additional level which mediates between a conceptualized event like the one presented in (10) and the linguistic knowledge we ascribe to the verb constructed from this event. This is the level of semantic representation. Thus, the process of noun-to-verb conversion may be schematized as follows: 
(11)

\author{
Level of conceptual QS of base noun \\ representation: \\ $\Downarrow$ \\ QS of conceptualized event \\ $\Downarrow$ \\ $\begin{array}{lll}\begin{array}{l}\text { Level of semantic } \\ \text { representation: }\end{array} & \text { Meaning Postulate } \Rightarrow \quad \begin{array}{l}\text { AS of denominal } \\ \text { verb }\end{array}\end{array}$ \\ Level of syntactic \\ representation
}

In this study, the QSs of conceptualized events like to BOTTLE are mapped onto Neo-Davidsonian meaning postulates, which are part of the semantic level of representation. The meaning postulates specify the number of semantic arguments involved in the events inferred from the QSs of the base nouns and reveal the roles the arguments assume within these events in the form of fine-grained thematic entailments. The manner of involvement is most adequately expressed by means of Dowty's (1991) theory of proto-roles. Dowty reduces the set of traditional thetaroles to two proto-roles, a proto-agent ( $\mathrm{p}$-agent) and a proto-patient ( $\mathrm{p}$ patient), which are defined over event-specific entailments and whose distribution is determined by an Argument Selection Principle (ASP). This principle roughly states that the argument having the greatest number of p-agent entailments will be realized as the subject and that the argument having the greatest number of p-patient entailments will surface as the direct object in syntax. Dowty (1991: 572) identifies the following sets of verbal entailments:

(12) Contributing properties for the Agent Proto-Role:
a. volitional involvement in the event or state
b. sentience (and/or perception)
c. causing an event or change of state in another participant
d. movement (relative to the position of another participant)
e. exists independently of the event named by the verb

(13) Contributing properties for the Patient Proto-Role:
a. undergoes change of state
b. incremental theme
c. causally affected by another participant
d. stationary relative to movement of another participant
e. does not exist independently of the event, or not at all 
In Baeskow (2002), proto-roles proved to be a most effective device for describing thematic relations determining the semantics of German and English person-denoting nouns. Only a few additional and well-motivated entailments had to be established in order to capture the wide spectrum of person-denoting nouns. One of these new entailments is 'impulse', which Engelberg substitutes for Dowty's entailment 'volition'. Based on biological evidence, Engelberg (2000: 206) successfully demonstrates that all human actions - even the ones performed unconsciously presuppose an impulse on the part of the agent, whereas volition is merely a concomitant factor. Another entailment added to (12) by Engelberg (2000: 211) is 'control', which indicates that the course and the duration of an event are determined by decisions and actions of the pagent. Furthermore, we require a p-agent entailment 'affection' and a corresponding p-patient entailment 'affected'. In contrast to 'causation' and 'causally affected', this pair expresses that the referent of the external argument $\left\langle\mathrm{x}^{\mathrm{ext}}\right\rangle$ interacts with the referent of the internal argument $\left\langle y^{\text {int }}\right\rangle$ without causing this entity to undergo a definite change of state (cf. Rauh 1988: 324, Engelberg 2000: 210, Baeskow 2002: 96 ff.). Protoroles, which will enter the meaning postulates of our denominal verbs, are superior to the traditional theta-roles such as Agent or Theme because they are well-motivated by the (slightly modified) sets of entailments.

Let us begin with the semantic analysis of the location verb to bottle. As outlined above, the TELIC quale of the concept BOTTLE (cf. (9)), which specifies the prototypical function of a bottle, gives rise to the conceptual event represented in (10) and repeated below as (14), in which this function is activated:

$$
\mathrm{QS}_{\text {то воттLе }}:\left(\begin{array}{rl}
\text { Formal } & =\operatorname{hold}(\mathrm{s}, \mathrm{z}: \text { phys_obj.con- } \\
& \text { tainer, } \mathrm{y} \text { : liquid }) \\
\text { AGENTIVE }= & \text { put }(\mathrm{e}, \mathrm{x}, \mathrm{y}, \mathrm{z})
\end{array}\right)
$$

As (14) suggests, the meaning postulate on which this conceptualized event of bottling is mapped must be defined as a complex semantic predicate which accounts for the activity performed by (x) of putting liquid (y) in a bottle (z) and for the resulting state of the bottle holding the liquid. Note that even the activity performed by $(\mathrm{x})$ is complex in itself because it consists of two temporally overlapping subevents $\left(\mathrm{e}^{\prime}\right)$ and $\left(\mathrm{e}^{\prime \prime}\right)$. In the first subevent, (x) acts on the liquid (y) and causes it to change its position. The referent of (y) is thus causally affected. The second subevent describes what Dowty (1991: 567) refers to as homomorphism. Related to our example to bottle and expressed in a somewhat simplified way, homomorphism means that the state of the bottle changes accord- 
ing to the amount of liquid put in. We start with an empty bottle - which is stationary relative to (the movement of) the liquid - and throughout the bottling-event, the content increases until the bottle is full. These considerations give rise to the following meaning postulate, which semantically reflects the conceptual relations expressed in (14) and which is part of the lexical entry of the denominal verb to bottle:

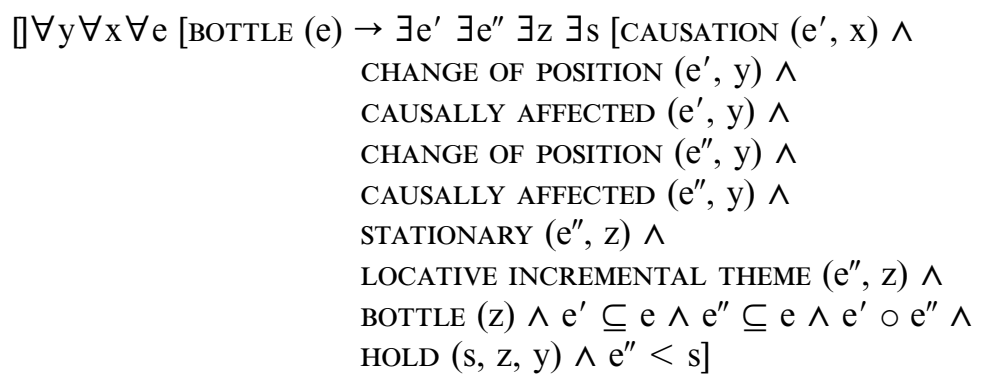

According to the ASP postulated by Dowty (1991), the semantic argument (x), for which to bottle entails the thematic relation 'causation', assumes the role of the proto-agent. As far as the proto-patient role is concerned, there are two potential candidates in (15), namely the semantic arguments (y) and (z), both of which have equal numbers of entailed proto-patient properties. However, (z) cannot be realized as an internal argument of to bottle because its position is occupied by the base noun itself. If at all, this semantic argument, which Pustejovsky (1996: 63 f.) refers to as a "shadow argument", is realized in the form of a prepositional object, as in (4a): The vinegar is then bottled in the traditional flask. In this case, the complement of the preposition is assigned the thematic relations 'stationary' and 'locative incremental theme' entailed for the shadow argument, which is legitimate because these relations are part of the semantic representation of the denominal verb. ${ }^{9}$

Note that the shadow arguments of location verbs do not generally qualify for incremental themehood. Consider verbs like to garage (the car), to kennel (the dog) or to jail (the man), which - unlike to bottle (the wine), to box (the salt) or to shelve (the books) - do not entail gradual occupancy of the space associated with the referents of their base nouns. Nevertheless, like BOTTLE (z), the shadow arguments of these verbs are assigned the thematic relation 'stationary' because their refer-

9. The fact that the location of the liquid may be a bottle-like container is not formally accounted for in the syntax-based approach of Hale \& Keyser because the base noun itself (in this case bottle) is spelt out within the N-node functioning as a complement to the hypothetical P-node in the lexicon (cf. (3)). 
ents are stationary relative to (the movement of) the referents of the verbs' internal arguments (car, dog, man etc.), for which they provide locations.

As a consequence of (15), (x) will be realized as the subject and (y) as the direct object of to bottle in the syntax. Moreover, it is assumed here that the semantic representation in (15) even makes predictions about three formal features (FFs) associated with to bottle. The first prediction concerns causativity. If the event of bottling entails 'causation' for the referent of its external argument and 'causally affected' for the referent of its internal argument, the verb must be causative in nature. In Baeskow $(2002,2004)$ and Baeskow (to appear), causativity is expressed by means of a FF [+ causative]. Secondly, the causative event represented in (15) reveals the aspectual nature of the verb to bottle. Like many other denominal verbs, to bottle is compatible with the progressive because it denotes a temporally structured event. In the terminology of Quirk et al. (1972) or Huddleston (1984), it constitutes a dynamic verb and hence specifies a formal feature [+dynamic] in its lexical entry. Thirdly, to bottle licenses an internal argument to which it assigns structural case. This property is made explicit by a FF [assign accusative] borrowed from Chomsky (1995: 231).

According to the OED, to bottle was first attested in 1641 and hence 266 years later than its nominal base, which was first attested in 1375. Thus, to bottle may be considered an Early Modern English formation. This etymological classification accounts for the fact that we are dealing here with a weak verb, which forms its past tense and past participle with the inflectional suffix $-e d$. In Baeskow (to appear), weak verbs are inherently specified for [-strong]. Given the information identified so far, the verb to bottle is assigned the following feature-based entry:

LEXICAL ENTRY FOR THE VERBAL ITEM TO BOTTLE

$$
\begin{array}{ll}
\text { orthographic representation: } & <\text { bottle }> \\
\text { phonological representation: } & / \mathrm{bpt}^{\mathrm{\imath} l} / \\
\text { set of formal features: } & {[+ \text { dynamic, +causative, }} \\
& \text { assign accusative, -strong }]
\end{array}
$$

semantic representation:

$\square \forall \mathrm{y} \forall \mathrm{x} \forall \mathrm{e}$ [BotTLe (e) $\rightarrow \exists \mathrm{e}^{\prime} \exists \mathrm{e}^{\prime \prime} \exists \mathrm{z} \exists$ s [CAusation $\left(\mathrm{e}^{\prime}, \mathrm{x}\right) \wedge$ CHANGE OF POSITION $\left(\mathrm{e}^{\prime}, \mathrm{y}\right) \wedge$ CAUSALLY AFFECTED $\left(\mathrm{e}^{\prime}, \mathrm{y}\right) \wedge$ CHANGE OF POSITION $\left(\mathrm{e}^{\prime \prime}, \mathrm{y}\right) \wedge$ CAUSALLY AFFECTED $\left(\mathrm{e}^{\prime \prime}, \mathrm{y}\right) \wedge$ STATIONARY $\left(\mathrm{e}^{\prime \prime}, \mathrm{z}\right) \wedge$ LOCATIVE INCREMENTAL THEME $\left(\mathrm{e}^{\prime \prime}, \mathrm{z}\right) \wedge$ BOTTLE (z) $\wedge \mathrm{e}^{\prime} \subseteq \mathrm{e} \wedge \mathrm{e}^{\prime \prime} \subseteq \mathrm{e} \wedge \mathrm{e}^{\prime} \circ \mathrm{e}^{\prime \prime} \wedge$ HOLD (s, z, y) $\wedge \mathrm{e}^{\prime \prime}$ $<\mathrm{s}]$

argument structure: $\quad<\mathrm{e}<\mathrm{x}, \mathrm{y}, \mathrm{z}>>$ 
Apart from the orthographic, phonological and morpho-syntactic representation, this entry specifies the meaning postulate of the verb to bottle, which was developed in (15) on the basis of conceptual information. The argument structure, which is inferred from the meaning postulate, reveals the number of arguments which have to be saturated in the syntax and thus reflects the syntactic part of the meaning postulate.

In order to prevent overgeneration of denominal verbs, it is supposed here that only established verbs are stored in the lexicon. This is what Lieber (2004: 94) refers to as relisting of nouns as verbs in the lexicon.

In a next step, consider the locatum verb to butter, which was classified as an ornative verb in section 2.2. The referent of the base noun butter is formally a kind of food substance which consists of cream, typically serves to cover a slice of bread and comes into being by beating mechanically the cream it consists of. Generic knowledge like this is represented in the form of the following QS:

$$
\mathrm{QS}_{\text {BUTter }}:\left(\begin{array}{ll}
\text { FORMAL } & =\text { food_substance }(\mathrm{z}) \\
\text { CONSTITUTIVE } & =\text { cream }(\mathrm{w}) \\
\text { TELIC } & =\text { cover }(\mathrm{e}, \mathrm{z}, \mathrm{y} \text { : slice_of } \\
& \text { _bread) } \\
\text { AGENTIVE } & =\text { beat }(\mathrm{e}, \mathrm{v} \text { : machine, } \mathrm{w})
\end{array}\right)
$$

In English, it is again the TELIC quale from which the concept of an event is created. Since the prototypical function of butter (or similar soft food substances) is to cover a slice of bread, the event the speakers of English associate with the referent of the noun butter is an act of putting butter on a slice of bread. This association is linguistically reflected by the collocation bread and butter. ${ }^{10}$ At the level of semantic representation, locatum verbs of the type to butter (as in to butter a slice of bread) differ from location verbs in that it is the referent of the shadow argument (z) that undergoes a change of position and is causally affected. The thematic relations 'stationary' and 'locative incremental theme' are entailed for the semantic argument (y) because the surface of the slice of bread, which is stationary relative to the referent of the shadow argument, is gradually covered with butter. In the syntax, $(\mathrm{x})$ is realized as the subject and (y) as the direct object of to butter.

10. Note that the formal representation of BUTTER as food_substance in (17) allows us to specify a VP whose head is to butter by means of a prepositional object, e. g. Jones buttered his toast with margarine. 


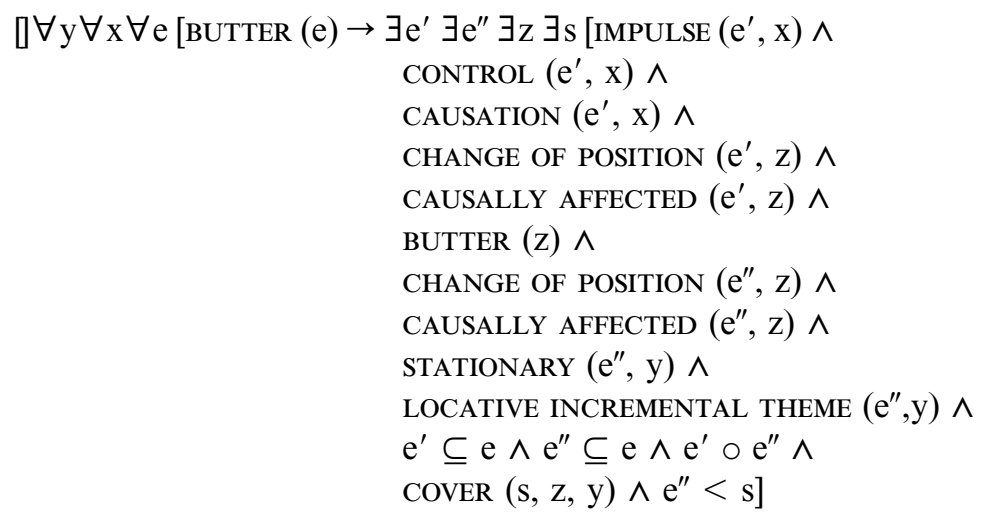

Other ornative locatum verbs such as to nickel, to wallpaper, to paint, to saddle, to label etc. are formed in the same way as to butter. Privative verbs, which constitute another subclass of locatum verbs, will be postponed until section 3.2. Note that the complex conceptual and semantic relations expressed by location and locatum verbs are not accounted for in the syntactic analyses proposed by Hale \& Keyser (1993, 1997, 2002), which postulate a structural analogy between the verbs of these two semantic classes and concrete verbs like put or provide with. Another shortcoming is that their theory is language-specific because it merely attempts to capture English denominal verbs. As pointed out above, the speakers of English associate the verb to butter with an event of putting butter on a slice of bread. In German, by contrast, the corresponding verb buttern refers to an event of producing butter, which emerges from the AGENTIVE quale of the nominal concept BUTTER rather than from the TELIC one. Thus, the QS of the nominal concept BUTTER is the same in both languages, but speakers of German create their event of buttering from a different quale than the speakers of English. The process of conversion splits at the stage of the QSs associated with the events denoted by the verbs to butter and buttern, and of course, the different conceptualized events lead to different semantic representations. In section 3.3. it will be shown that there are also instances of language-internal variation as to the selection of a particular quale.

However, if the referent of the base noun serves a particular purpose, it is usually the TELIC quale of the nominal concept which gives rise to the event denoted by the denominal verb in English and in German. This is true especially of the large number of instrumental verbs (e.g. to hammer, to nail, to knife, to bicycle, to guitar in English), all of which denote events in which the prototypical functions of the referents of the base nouns are activated. 
From a conceptual and semantic point of view, the verbs referred to as agent verbs in section 2.2. (e. g. to author, to father, to pioneer) are of particular interest. Let us discuss the example to author in more detail. Within the QS of the base noun, the referent of AUTHOR is first of all classified as a human being. Hence, the FORMAL quale specifies the qualia value "human (x)". Of course, this information is not sufficient to distinguish an author from other human beings. What is important about the concept AUTHOR is the activity of writing. But which quale is responsible for the representation of this activity? Is it the TELIC or the AGENTIVE one? A reasonable answer is provided by Pustejovsky (1996: $229 \mathrm{f}$.). Analogously to the differentiation between stage-level and individuallevel predicates first postulated by Carlson (1977), Pustejovsky distinguishes between stage-level nominals (SLNs) like pedestrian, passenger or customer and individual-level nominals (ILNs) like violinist, physician or linguist. SLNs are interpretable only with respect to a temporary activity their referents are involved in at the time of reference. For instance, a human being can only be referred to as a pedestrian if he or she is involved in a walking event. On the other hand, ILNs are interpretable independently of the activity performed at the time of reference because they have generic character. Hence, a sentence like The violinist is eating lunch at the cafeteria is semantically well-formed in spite of the fact that a violinist is typically associated with the activity of playing the violin. As a consequence, the activities associated with the "situationally-defined" SLNs are represented on the AGENTIVE quale of the nominal concepts, whereas the activities typically associated with the "role-defining" ILNs are represented on the TELIC quale of the nominal concepts. As far as the base noun of to author is concerned, it is assumed here that we are dealing with an ILN because its reference is not restricted to a temporary event of writing. The event of writing a text rather defines the "function" of an author and should thus be represented on the TELIC quale of the nominal concept AUTHOR.

$$
\text { QS } \text { AUTнов: }:\left(\begin{array}{l}
\text { FORMAL }=\operatorname{human}(\mathrm{x}) \\
\text { TELIC }=\operatorname{write}(\mathrm{e}, \mathrm{x}, \mathrm{y}: \text { text })
\end{array}\right)
$$

The process of verbalization begins by forming a conceptual event of writing, which is picked up from the TELIC quale in (19) and enters the AGENTIVE quale of TO AUTHOR in (20). The reason is that the event of writing, which defines the function of the nominal concept AUTHOR, also defines the coming about of the verbal concept TO AUTHOR.

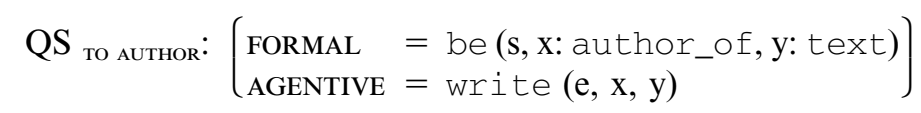


Note that TO AUTHOR has both a dynamic and a stative reading. On the one hand, it refers to the event of writing, but on the other hand, it is also compatible with a reading in which the state of being an author is focussed. However, these different perspectives are not independent of each other because the state of being an author presupposes that a writing event has taken place. Within a qualia-based approach, this ambivalence is accounted for by representing the activity and the resulting state on different quales.

The semantic meaning postulate of the converted verb to author mirrors the relations expressed in (20). The referent of $(\mathrm{x})$ performs a causative action which gradually leads to the existence of $(y)-a$ piece of writing. According to the thematic constellations, (x) is the proto-agent and (y) the proto-patient. The meaning postulate also reveals that every event denoted by to author involves a state (s) which temporally follows (e) and in which the referent of (x) is the author of the text he or she produced.

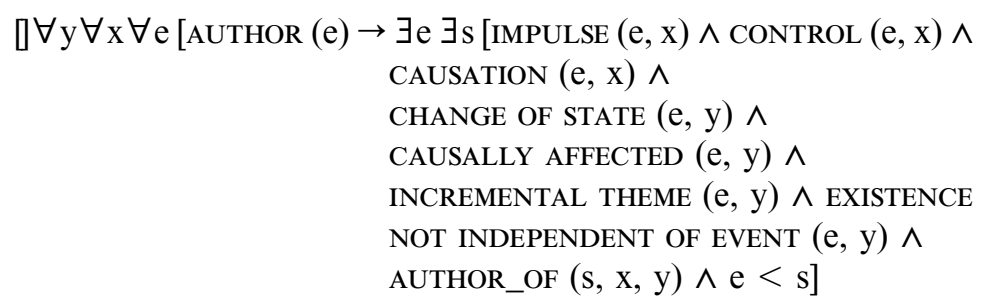

Agent verbs like to father or to pioneer, which occur e. g. in (22), are described analogously to the verb to author.

(22) a. Bevan fathered the concept of the National Health Service. (DCE)

b. The new cancer treatment was pioneered in the early eighties by Dr Sylvia Bannerjee. (DCE)

The English denominal verbs analysed so far were constructed from the TELIC quale of the concepts denoted by their nominal bases. However, as indicated already in the context of the German verb buttern, denominal verbs also activate quales other than the TELIC one. Consider e. g. the resultative verb to beggar. Since poverty is a constitutive factor of a beggar, the meaning "to make someone poor" of the corresponding verb arises from the CONSTITUTIVE quale of the base noun. The QS of beggar can be represented as in (23): 
Reflections on Noun-to-Verb Conversion In English

$$
\mathrm{QS}_{\text {BEGGAR }}:\left(\begin{array}{ll}
\text { FORMAL } & =\operatorname{human}(\mathrm{x}) \\
\text { CONSTITUTIVE } & =\text { poor }(\mathrm{x}) \\
\text { AGENTIVE } & =\text { beg_for }(\mathrm{e}, \mathrm{x}, \mathrm{y} \text { : goods })
\end{array}\right)
$$

These examples should suffice to show that the events typically associated with converted denominal verbs arise from particular quales of the base nouns. Since QSs capture what Karius (1985: 50) describes as the constant core of a frame (cf. section 2.3.), they may actually be thought of as formalized frames. The qualia values are comparable to Minsky's (1982) "default assignments" because they reflect the speakers' expectations about objects and the events these objects are stereotypically involved in and thus help to conceptualize a particular object from various perspectives. ${ }^{11}$

\subsection{The relevance of the syntactic context}

Apart from generic knowledge, there is yet another aspect which contributes to an adequate interpretation of denominal verbs. This is the syntactic context in which a denominal verb appears. In particular, it is the syntactically realized internal argument of a verb which deserves special attention. Consider e.g. the following sentence cited from Karius (1985: 131).

The woodcutters barked the trees.

In section 2.2. it was pointed out that privative verbs like to bark, to skin, to fleece, to peel or to shell constitute another subclass of locatum verbs, which differ from ornatives by expressing an entity's removal from a certain position. Interestingly, the base nouns of these verbs denote "natural kinds" in the sense of Pustejovsky (2003). Thus, they do not serve a specific purpose in a way that physical objects do, but display a built-in aim or function, for "nature makes everything for the sake of something" (Moravcsik 1975: 627, cited from Aristotle). Since such an inherent function is not activated by human agents or machines, the TELIC quale of a noun like bark, which specifies a built-in function, does not determine the semantics of the corresponding verb.

$$
\text { QS }_{\text {BARK }}: \quad\left(\begin{array}{l}
\text { FORMAL }=\text { part_of_tree.tissue }(\mathrm{z}) \\
\text { TELIC }=\text { cover }(\mathrm{e}, \mathrm{z}, \mathrm{y}: \text { tree })
\end{array}\right)
$$

11. The relevance of expectations in approaches to knowledge representation and other scientific domains is emphasized by Tannen (1993). 
The conceptual event of removing the bark from a tree is properly accounted for only if we extend our view from the base noun to the QS of the noun tree, which realizes the conceptual internal argument of "cover" in (25). Since the bark is a constitutive factor of trees and thus in a natural part-whole relation with trees, it is improbable that the woodcutters provided the trees with bark. They rather did the opposite by removing the bark from its source position. The same assumption holds for the other privative verbs which are formed from nouns denoting natural kinds. Note that in (25), the less botanical type "tissue" in the FORMAL quale of the base noun bark, which yields one of the two senses associated with that noun, accounts for the figurative interpretation of phrases like to bark one's shin/kneelelbow etc. Semantically, privative locatum verbs differ from ornative locatum verbs only with respect to the resulting state, which is a negative one in the case of to bark, to skin, to fleece, to peel, to shell etc. Thus, their meaning postulates are analogous to the one presented for to butter in (18), but involve the negation of the resulting state, i. e. $[\neg \operatorname{COVER}(\mathrm{s}, \mathrm{z}, \mathrm{y}) \ldots]$.

The syntactic context also helps to disambiguate denominal verbs which can in principle be assigned to two semantic classes. Disambiguation of these verbs is easily achieved if the QSs of the referents of the internal arguments are taken into consideration. Examples are provided by the following sentences:

a. Jim milked the cow.

b. Miss Marple milked her coffee.

a. Mary feathered a goose.

b. Wild Horse feathered his arrow.

(28) a. Aunt Agatha stoned the cherries.

b. The mob stoned the witch.

In the a.-sentences, the referents of the verbs' base nouns are in a partwhole relation with the referents of the internal arguments and thus appear on the constitutive quale of these nominal concepts. Milk is a constitutive factor of the concept cow, feathers are a constitutive factor of the concept GOOSE, and a stone is a constitutive factor of the concept CHERRY. As a result, an ornative reading is blocked in these sentences, and like to bark, the denominal verbs are contextually interpreted as privative verbs.

The metonymic relations observed in the a.-sentences do not hold in the b.-sentences because milk, feathers and stones do not constitute components of the concepts COFFEE, ARROW and WITCH respectively. Thus, a privative interpretation is blocked. Note that the referents of milk, 
feather and stone (the latter in either of the readings "a small piece of rock" and "a large hard single seed at the centre of some fruits", cf. DCE) are natural kinds and thus behave like the noun bark discussed above in that they merely display built-in functions. If the speakers of English form non-privative conceptual events from nominal concepts like MILK, FEATHER Or STONE, they associate these concepts with an imposed telic in the sense of Pustejovsky (2003). An imposed telic is a function contextually coerced on an entity and thus a function which is not inherent to the TELIC quale of this entity. A feather, for instance, has the built-in function of covering the body of a bird, which is specified on the TELIC quale of the nominal concept FEATHER. In a context like (27b), this natural function is overridden by an imposed telic according to which a feather serves to decorate the object denoted by the internal argument arrow. The conceptual event constructed from the imposed telic is thus an event of decorating. Similarly, the ornative reading of to milk in (26b) results from the fact that a function of modifying the taste of coffee is imposed on the nominal concept MILK. The referent of stone "a small piece of rock" displays a built-in function which is optimally explained by a geologist. In a context like (28b), the nominal concept STONE is associated with the function of hitting someone, which is due to the physical qualities of stones. This imposed function gives rise to an event in which the referent of stone is an object that is thrown. The process of constructing an event from a non-inherent and hence imposed telic of a nominal concept, which is responsible for the ornative reading of to milk in (26b) and to feather in (27b) as well as for the instrumental reading of to stone in (28b), will be referred to here as functional coercion. Note that it is exactly the reference to context - in particular to the verb's internal argument - which makes the notion of QS so useful not only for the interpretation of syntactic structures (cf. Pustejovsky 1996, 1998), but also for the interpretation and formation of denominal verbs.

\subsection{Neologisms and innovative uses of institutionalized verbs}

A considerable advantage of QSs is their analytical and generative force. On the one hand, they explain where the institutionalized event-readings of established verbs come from. The selection of a particular quale associated with a nominal concept and the conceptualization of an event from this quale is normally governed by usage. On the other hand, QSs provide options for the interpretation of innovative verbs, which are either neologisms or established verbs used in an innovative way. Both kinds of innovative verbs will be discussed in this section. In order to reveal the conceptual nature of (fairly) new denominal verbs, let us pick out some examples from the list of $20^{\text {th }}$ century neologisms provided by 
Plag (1999: $274 \mathrm{ff}$.$) . As with established verbs, neologisms whose base$ nouns denote entities serving a particular purpose frequently acquire their meaning from the base noun's TELIC quale. Examples are to jet, to microwave, to stop-watch, to gramophone, to video, to centrifuge, to postcard or to sauna. The same holds for verbs whose bases denote an organ (e. g. to eyeball "to look or stare (at)", to guts "to eat greedily, to gormandize", to nostril "to inhale or exhale through the nose") and for agent verbs like to secretary, to hostess or to monger. Verbs of this kind are readily computed even in isolation because they express what we expect the referents of the base nouns to be used for or to do.

However, as pointed out in the previous section, the interpretation of denominal verbs is sometimes constrained by the syntactic context. Depending on the base noun's QS, a new denominal verb encountered in isolation may in principle be associated with one of at least four meaning components. ${ }^{12}$ A good example is the verb to sherry, which the OED classifies as a nonce-word and whose base noun displays the following QS:

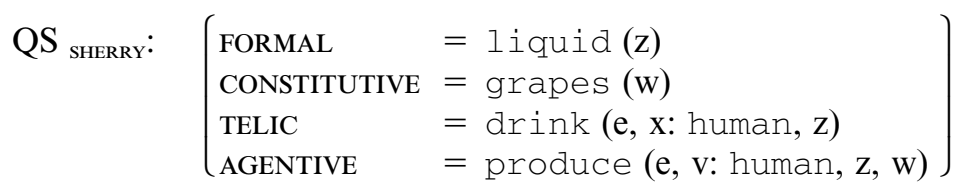

Since each quale provides an option for the interpretation of to sherry, this verb may assume meaning components like "to produce sherry" (AGENTIVE), "to drink sherry" (TELIC), "to select grapes in order to make a sherry-like drink" (CONSTITUTIVE) or "to pour sherry into a glass" (FORMAL). However, when to sherry was recorded for the first time in 1909, it occurred in the following sentence (cf. OED):

(30) Nursed by a careful butler [...] a single bottle will sherry twelve guests.

None of the potential meaning components suggested above matches the meaning of to sherry in (30). The reason is that the meaning "to supply with sherry" results from the verb's internal argument twelve guests. Note however that even this context-dependent interpretation is retrievable from the QS in (29). Since sherry functions as a beverage, to sherry at

12. In this respect, new denominal verbs are comparable to novel NN compounds, which are also highly polysemous in isolation (cf. Meyer 1994 for German). 
least implies what the guests are expected to do with the referent of the base noun. Moreover, to sherry the guests could be seen as analogous to the phrase to water the horse (Colin Foskett, p.c.).

Next, consider neologisms like to guitar, to saxophone or to zither "to play the guitar/saxophone/zither", which most naturally activate the TELIC value "produce (e, z: musical_instr, y: sound)" of their respective base nouns. And yet, the verb to concertina does not follow this pattern in contexts like to concertina the place-card (Clark \& Clark 1979: 775) or to concertina the opera-hat (OED). Again, the QS of the base noun provides another option: ${ }^{13}$

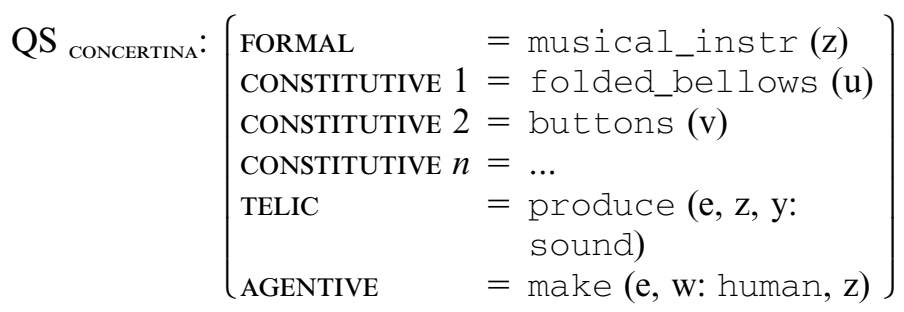

Since neither place-cards nor hats produce sounds, but consist of material which may be wrinkled in a manner resembling the bellows of a concertina, this verb must relate to the value of the base noun's first CONSTITUTIVE quale. It is not the buttons or the other parts of a concertina, but the folded bellows that are obviously considered to be the distinguishing feature of this instrument. Accordingly, this is the feature focussed on by the verbalization process.

As indicated in section 3.1., QSs are comparable to frames because they specify world knowledge in the form of default values. If we encounter an established verb with a lexically-fixed meaning in an appropriate context, the expectations we have about the referent of the base noun and the referents of the syntactic arguments are met because the syntactic context is compatible with the relations specified in a particular quale. For instance, They bottled the wine is readily computable because wine denotes a liquid and hence matches the conceptual internal argument "y: liquid" of the value "hold" in the TELIC quale of bottle (cf. (9)).

As far as the interpretation of neologisms is concerned, there is more flexibility because our expectations are not restricted to a particular quale unless such a quale is activated by the syntactic context (e.g. $\mathrm{He}$

13. In (31), the CONSTITUTIVE quale is split up into $n$ sub-quales because the distinctive properties associated with the concept CONCERTINA are too complex to be represented on a single quale. 
concertinaed his place-card). It is assumed here that neologisms enter the lexicon with a fixed semantic representation as soon as they have undergone institutionalization, i. e. as soon as they are part of the active vocabulary of the speakers of English. The claim for a lexical representation distinguishes institutionalized denominal verbs from the huge number of potential denominal verbs or ad hoc-formations, which only exist at the level of conceptual representation.

A final aspect (which was mentioned by an anonymous reviewer and which will be discussed briefly) concerns the interpretation of denominal verbs in a context which goes beyond the limits of a sentence, i. e. in the context of discourse. Consider the following sentence, which is the result of a search performed using Google:

[...] Several people saw them down the lane isolated, and the next thing they were being stoned and bottled by people steaming up the laneway. $[\ldots]^{14}$

In this case, the prototypical function associated with the referent of the base noun bottle is overridden by the linguistic context and discourse. World knowledge tells us that it is highly improbable that the referents of we were put in bottles for preservation. But even a sentence like (32) may be disambiguated by means of the qualia concept if we assume that the base noun bottle, like the base noun of the preceding verb to stone, is associated with an imposed telic. An adequate TELIC value is retrievable from what Meyer (1993) refers to as discourse knowledge. This is the information given in the preceding or immediately following discourse. A closer examination of the report containing the sentence in (32) actually reveals some clues as to the function imposed on the referent of bottle. First of all, the setting of the situation described in the text is the following: "A mini riot erupted in Rose Street, at the St Andrews Square end, in the early evening, around $6.30 \mathrm{pm}$. [...]" World knowledge enables us to conceptualize not only concrete entities like those denoted by the base nouns of denominal verbs, but also stereotyped situations like the one denoted by riot. The ensemble of a situation is representable in a frame as well, but here we are dealing with a particular frame which is more adequately referred to as a script. Shank \& Abelson (1977: 41), who first introduced this term, define a script as "a predetermined, stereotyped sequence of actions that defines a well-known situation." Nothing will be said here about the formal details of a script,

14. A similar example is provided by Clark \& Clark (1979: 785) without discourse information. 
which are discussed e. g. by Shank \& Abelson (1977) and Meyer (1993). For our purposes, it should be sufficient to state pre-theoretically that a 'riot'-script typically involves a crowd of people, some degree of violence, police officers and the throwing of objects. The interpretation of to bottle in (32) is strongly influenced by the script-condition "throwing of objects", which suggests that the imposed telic of the base noun is "pelt_with". In fact, this hypothesis is confirmed in the sentence immediately following (32). "Bottles were fired at them [i.e. at the cops] from close range [...]." This instance of functional coercion, which yields the alternative instrumental interpretation "to pelt someone/something with a bottle", is first of all due to the 'physical object-reading' of the base noun. Recall that bottle is a complex type consisting of the senses physical_object and container, the former of which is focussed in (32). Secondly, the prototypical bottle was said to consist of glass (cf. (9)) and thus of a material (specified within the constitutive quale) which is hard enough to be used to hit other people. This example, to which we might add phrases like to hairpin the lock open, to teapot a policeman, to pie the woman in a local doughnut store (Clark \& Clark 1979: 786) or to shelve a plan (Patrick Deegan, p.c.), all of which are not accounted for in a strictly syntax-based approach as proposed by Hale \& Keyser, confirms that different readings of the same denominal verb arise by focussing different quales of the base nouns. This fact also accounts for the language-specific interpretations of the verbs to butter and buttern in English and German discussed in section 3.1.

\section{Summary}

In this study, a new analysis for denominal verbs formed by means of conversion has been presented. In the framework proposed here, the option of creating expressions for events from nouns without verbalizing suffixes is provided by the nouns' qualia structures. The qualia structure of a noun defines the characteristics of a nominal concept on the basis of up to four generative factors, which are represented on corresponding conceptual quales, and each quale can in principle serve as a startingpoint for the conceptualization of an event. The conceptual event constructed from a particular quale of the base noun is mapped onto a NeoDavidsonian meaning postulate, which is located at the level of semantic representation and which quantitatively and thematically specifies the participants involved in this event. Since meaning postulates represent the semantics of established denominal verbs, they function as mediators between the level of conceptual representation and the argument structures the verbs finally display in their lexical entries. Moreover, it is 
assumed here that the meaning postulate of a denominal verb also has consequences for the verb's set of formal features.

In order to avoid overgeneration of denominal verbs, it was argued that only established verbs are listed in the lexicon with their institutionalized meanings. The meaning of an established verb arises from a particular quale of the base noun, which is fixed by usage. As far as neologisms are concerned, all the quales of the base noun constitute options for potential readings. These options are also employed when innovative meaning components are assigned to established denominal verbs via functional coercion (e.g. to bottle "to pelt with bottles"). Finally, it should be pointed out that converted verbs are not exclusively formed from nouns. Examples like to empty, to clean, to calm, to down, to out or to off show that adjectives and (less frequently) prepositions may be changed into verbs as well. ${ }^{15}$ Of course, converted verbs that are not denominal must be left to future investigation, but at this point it should be mentioned that qualia structures are not restricted to nouns and to the events constructed from nouns. Thus, they might also be involved in the construction of events from non-nominal bases. The QSs of some adjectives are discussed by Pustejovsky (1996) and McNally (2004), and prepositional QSs are dealt with in Kurtz \& Pötter (1998). The present study is an attempt to show that qualia structures - sometimes supported by the syntactic context or the discourse context - are a useful device to explain the interpretation and formation of denominal verbs formed by means of conversion.

Eingereicht: 30. März 2005

Überarbeitete Fassung eingereicht:

23. März 2006

\section{References}

Adams, Valerie (1973). An Introduction to Modern English Word-Formation. London: Longman.

Anick, Peter \& James Pustejovsky (1990). An application of lexical semantics to knowledge acquisition from corpora. In Proceedings of the $13^{\text {th }}$ International Conference on Computational Linguistics, University of Helsinki, Finland 1990, Hans Karlgren (ed.), 7-12.

Baeskow, Heike (2002). Abgeleitete Personenbezeichnungen im Deutschen und Englischen. Kontrastive Wortbildungsanalysen im Rahmen des Minimalistischen Programms und unter Berücksichtigung sprachhistorischer Aspekte. Berlin: Walter de Gruyter.

Baeskow, Heike (2004). Lexical Properties of Selected Non-native Morphemes of English. Tübingen: Narr.

Baeskow, Heike (to appear). A revival of Romance roots. (Yearbook of) Morphology.

Bauer, Laurie (1988). Introducing Linguistic Morphology. Edinburgh: Edinburgh University Press.

15. As revealed by Plag (2004), derivatives show a similar flexibility as to their input. 
Bierwisch, Manfred (1997). Lexical information from a minimalist point of view. In The Role of Economy Principles in Linguistic Theory, Chris Wilder, Hans-Martin Gärtner \& Manfred Bierwisch (eds.), 227-266. Berlin: Akademie Verlag.

Borer, Hagit (2005). In Name Only. Oxford: Oxford University Press.

Burgschmidt, Ernst (1975). System, Norm und Produktivität in der Wortbildung, Seminar für Englische Philologie, Erlangen.

Carlson, Greg (1977). Reference to Kinds in English. Unpublished Ph.D. dissertation, University of Massachusetts.

Chomsky, Noam (1986). Knowledge of Language. Its Nature, Origin and Use. New York: Praeger.

Chomsky, Noam (1995). The Minimalist Program. Cambridge, MA: The MIT Press.

Clark, Eve \& Herbert Clark (1979). When nouns surface as verbs. Language 55: 767-811.

Dirven, René (1999). Conversion as a conceptual metonymy of event schemata. In Metonymy in Language and Thought, Klaus-Uwe Panther \& Günter Radden (eds.), 275287. Amsterdam: Benjamins.

Dokulil, Milos (1968). Zur Frage der sog. Nullableitung. In Wortbildung, Syntax und Morphologie: Festschrift für Hans Marchand, Herbert Brekle \& Leonhard Lipka (eds.), 5564. The Hague: Mouton.

Dowty, David R. (1991). Thematic proto-roles and argument selection. Language 67: 547-619.

Engelberg, Stefan (2000). Verben, Ereignisse und das Lexikon. Tübingen: Niemeyer.

Grice, H. Paul (1975). Logic and conversation. In Syntax and Semantics 3: Speech Acts, Peter Cole \& Jerry L. Morgan (eds.), 41-58. New York: Academic Press.

Hale, Ken \& Samuel J. Keyser (1993). On argument structure and the lexical expression of syntactic relations. In The View from Building 20. Essays in Linguistics in Honor of Sylvain Bromberger, Ken Hale \& Samuel J. Keyser (eds.), 53-109. Cambridge, MA: The MIT Press.

Hale, Ken \& Samuel J. Keyser (1997). On the complex nature of simple predicators. In Complex Predicates, Alex Alsina, Joan Bresnan \& Peter Sells (eds.), 29-65. Stanford: CSLI Publications.

Hale, Ken \& Samuel J. Keyser (2002). Prolegomena to a Theory of Argument Structure. Cambridge, MA: The MIT Press.

Huddleston, Rodney (1984). Introduction to the Grammar of English. Cambridge: Cambridge University Press, reprinted 1989.

Jackendoff, Ray (1987). The status of thematic relations in linguistic theory. Linguistic Inquiry $18,369-411$.

Jackendoff, Ray (1990). Semantic Structures. Cambridge, MA: The MIT Press.

Jackendoff, Ray (1997). The Architecture of the Language Faculty. Cambridge, MA: The MIT Press.

Jespersen, Otto (1942). A Modern English Grammar on Historical Principles. Part VI: Morphology. London: George Allen \& Unwin Ltd., reprinted 1974.

Karius, Ilse (1985). Die Ableitung der denominalen Verben mit Nullsuffigierung im Englischen. Tübingen: Niemeyer.

Kiparsky, Paul (1997). Remarks on denominal verbs. In Complex Predicates, Alex Alsina, Joan Bresnan \& Peter Sells (eds.), 473-499. Stanford: CSLI Publications.

Kurtz, Gunde \& Pötter, Thomas (1998): Generative semantics for prepositions, prefixes, and compounds. SDV - Sprache und Datenverarbeitung. International Journal for Language Data Processing 2: 58-80.

Labelle, Marie (2000). The semantic representation of denominal verbs. In Lexical Specification and Insertion, Peter Coopmans, Martin Everaert \& Jane Grimshaw (eds.), 215240. Amsterdam: Benjamins.

Lieber, Rochelle (1981). On the Organization of the Lexicon. Bloomington: Indiana University Linguistics Club (IULC). 
Lieber, Rochelle (2004). Morphology and Lexical Semantics. Cambridge: Cambridge University Press.

Maienborn, Claudia (1996). Situation und Lokation. Die Bedeutung lokaler Adjunkte von Verbalprojektionen. Tübingen: Stauffenburg.

Marchand, Hans (1969). The Categories and Types of Present-Day English Word-Formation A Synchronic-Diachronic Approach. München: C. H. Beck'sche Verlagsbuchhandlung, second edition.

McNally, Louise (2004): Lexical representation and modification within the NP, http://mutis.upf.es/ mcnally/mcnally-rlv.doc

Meyer, Ralf (1993). Compound Comprehension in Isolation and in Context. The contribution of conceptual and discourse knowledge to the comprehension of German novel noun-noun compounds. Tübingen: Niemeyer.

Minsky, Marvin (1982). A framework for representing knowledge. In Mind Design: Philosophy, Psychology, Artificial Intelligence, John Haugeland (ed.), 95-128. Cambridge, MA: The MIT Press.

Moravcsik, Julius M. (1975). Aitia as Generative Factor in Aristotle's Philosophy. Dialogue 14: $622-636$

Moravcsik, Julius, M. (1981). How do words get their meanings? Journal of Philosophy 78: $5-24$.

Moravcsik, Julius, M. (1990). Thought and Language. London: Routledge.

Olsen, Susan (1986). Wortbildung im Deutschen. Stuttgart: Alfred Kröner Verlag.

Plag, Ingo (1999). Morphological Productivity. Structural Constraints in English Derivation. Berlin: Mouton de Gruyter.

Plag, Ingo (2003). Word-Formation in English. Cambridge: Cambridge University Press.

Plag, Ingo (2004). Syntactic category information and the semantics of derivational morphological rules. Folia Linguistica XXXVIII/3-4, 193-225.

Pustejovsky, James (1996). The Generative Lexicon. Cambridge, MA: The MIT Press, second printing.

Pustejovsky, James (1998). Generativity and explanation in semantics: A reply to Fodor and Lepore. Linguistic Inquiry 29: 289-311.

Pustejovsky, James (2001). Type construction and the logic of concepts. In The Language of Word Meaning, Federica Busa \& Pierrette Bouillon (eds.), 91-123. Cambridge: Cambridge University Press.

Pustejovsky, James (2003). Categories, Types, and Qualia Selection. In Asymmetry in Grammar, Volume 1. Syntax and Semantics, Anna Maria Di Sciullo (ed.), 373-393. Amsterdam: Benjamins.

Quirk, Randolph, Sidney Greenbaum, Geoffrey Leech \& Jan Svartvik (1972): A Grammar of Contemporary English. London: Longman.

Rauh, Gisa (1988). Tiefenkasus, thematische Relationen, Thetarollen. Die Entwicklung einer Theorie von semantischen Relationen. Tübingen: Narr.

Rauh, Gisa (2000). Don't call it 'X'! or: Why X does not represent grammatical categories. In Verbal Projections, Hero Janßen (ed.), 1-21. Tübingen: Niemeyer.

Sanders, Gerald (1988). Zero derivation and the Overt Analogue Criterion. In Theoretical Morphology: Approaches in Modern Linguistics, Michael Hammond \& Michael Noonan (eds.), 155-175. San Diego: Academic Press, Inc.

Shank, Roger C. \& Robert P. Abelson (1977). Scripts, Plans, Goals and Understanding. An Inquiry into Human Knowledge Structures. Hillsdale, New Jersey: Lawrence Erlbaum Associates.

Stiebels, Barbara (1998). Complex denominal verbs in German and the morphology-semantics interface. In Yearbook of Morphology 1997, Geert Booij \& Jaap van Marle (eds.), 265-302. Dordrecht: Kluwer.

Summers, Della et al. (1995). Longman Dictionary of Contemporary English. München: Langenscheidt-Longman GmbH. 
Tannen, Deborah (1993). What's in a frame? Surface evidence for underlying expectations. In Framing in Discourse, Deborah Tannen (ed.), 14-56. Oxford: Oxford University Press.

Williams, Edwin (1981). Argument structure and morphology. The Linguistic Review 1: $81-114$.

Zandvoort, Rainard W. (1972). A Handbook of English Grammar. London: Longman.

OED online:http://dictionary.oed.com

BNC World Edition: December 2000 Release

SARA version 0.98 (Published by the Humanities Computing Unit of Oxford University on behalf of the BNC Consortium) 